\title{
A MONITORIA COMO ESTRATÉGIA NO ENSINO-APRENDIZA- GEM DA SOCIOLOGIA: PRIMEIRAS APROXIMAÇÕES
}

\author{
MONITORSHIP AS A STRATEGY FOR THE TEACHING AND LEARNING OF \\ SOCIOLOGY: first approaches
}

\section{LA MONITORIA COMO ESTRATEGIA DE ENSENÃNZA-APRENDIZAJE SO- CIOLOGÍA: primeras aproximaciones}

\author{
Maria Antoniêta Albuquerque de Souza \\ Professora Doutora da Universidade de Pernambuco (UPE). \\ antonieta.albuquerque@upe.br \\ Virgínia Pereira da Silva de Ávila \\ Professora Doutora da Universidade de Pernambuco (UPE). \\ virginia.avila@upe.br
}

\begin{abstract}
RESUMO: O texto discute a possibilidade de favorecimento à positividade do ensino e da aprendizagem da Sociologia, no Ensino Médio, pelo exercício da monitoria. Toma como base a leitura de relatos de experiências e de pesquisas que analisam as atividades de monitoria como um importante instrumento de aprendizagem na formação e no desenvolvimento acadêmico Matoso (2014), Mascarenhas (2012), Frison e Moraes (2010), Oliveira e Jardim (2008). Centra-se na análise da relação entre a forma de ensino monitoria e o status (lugar) dessa disciplina no Ensino Médio, e, em menor proporção, no Superior, realçando o processo de "autorregulação". Por fim, considera que o ajustamento de medidas interativas na comunicação entre alunos e professores, assim como na organização de conteúdos curriculares, pode contribuir com a produção de significados no processo de ensino-aprendizagem dos alunos de Ensino Médio.
\end{abstract}

PALAVRAS-CHAVE: Sociologia. Ensino Médio. Monitoria.

ABSTRACT: The text studies the possibility of favoring the positive aspect in the teaching and learning of Sociology in High School through the practice of monitorship. It is based on the reading of experience and research reports that analyse monitorship activities as an importante learning device for academic formation and development (Matoso (2014), Mascarenhas (2012), Frison and Moraes (2010), Oliveira and Jardim (2008). It focus on the analysis of the relation between monitorship as a teaching tool and the status this subject holds in High School - and Undergraduation, reinforcing the self-regulation process. Finally, it considers that the adjustment of interactive manners in the communication among students and teachers, as well as in the organization of syllabus, may contribute to the production of meaning in the learning and teaching processes of High School students.

KEYWORDS: Sociology. High School. Monitorship.

RESUMEN: El texto discute la posibilidad de favoritismo a la positividad de la enseñanza y el aprendizaje de la sociología, en la escuela secundaria, por el ejercicio de la monitoria. Emparte como base, la lectura de ralatos de experiências y de pesquisas que analizan las actividades de vigilancia como herramienta de aprendizaje importante en el desarrollo académico y capacitación (Matoso (2014), Mascarenhas (2012), Frison y Moraes (2010), Oliveira y el Jardín (2008). Se centra en el análisis de la relación entre la forma de enseñanza de monitoria y el estatus o lugar de esa asignatura en la escuela secundaria y, en menor proporción, en la enseñanza superior, mejorando el proceso de "autorregulación". Por último, considera que el ajuste de medidas interactivas en la comunicación entre estudiantes y profesores, así como, en la organización del contenido curricular, puede contribuir a la producción de significado en el proceso de enseñanza-aprendizaje de los estudiantes de enseñanza secundaria.

PALABRAS CLAVE: Sociología. Enzenãnza secundaria. Monitoria.

Artigo recebido em setembro de 2016

Aprovado em novembro de 2016 
A MONITORIA | Maria Antoniêta Albuquerque de Souza e Virgínia Pereira da Silva de Ávila

\section{1| O STATUS DA SOCIOLOGIA NO CAMPO DISCIPLINAR: do Ensino Médio ao Superior}

A reflexão sobre o ensino da Sociologia no Ensino Médio (EM) (e Graduação)', no Brasil, depara-se com os registros das suas idas e vindas no currículo oficial das escolas. Do cerne dessa questão, sobressaem duas justificativas para a explicação das dificuldades que encerram a inclusão da disciplina. A primeira está relacionada à preparação do docente de Sociologia e a segunda, por conseguinte, se localiza nos possíveis efeitos na prática de ensino: a inadequação metodológica e a abstração teórica e conceitual.

Não obstante essas questões venham sendo discutidas pelos sociólogos e cientistas sociais (com lugar específico, inclusive, nos últimos congressos brasileiros de Sociologia promovidos pela SBS - Sociedade Brasileira de Sociologia), a problemática aqui referida tem por cenário a prática do ensino da disciplina Sociologia e da experiência discente de monitoria em cursos de graduação da área de Saúde ${ }^{2}$. Traços da persistência da problemática apresentada vêm, ainda, revestindo a prática da docência, e configurando o estatuto disciplinar da Sociologia no sistema de ensino brasileiro, o que contribui para a negatividade de sua imagem frente aos alunos e, talvez, docentes de outras disciplinas não afins. Justamente, as seguidas pré-indisposições dos alunos para cumprir os créditos de Sociologia e as características da experiência de mediação da monitoria acadêmica na disciplina induziram ao aprofundamento dos problemas que circulam as dificuldades do ensino-aprendizagem do componente curricular.

Com características de artigo de revisão assistemática, o texto se desenvolve preocupado em oferecer uma visão que indique condições de possibilidade no ensino de Sociologia, senão novas mais favoráveis à sua aprendizagem. Isso produz efeitos sobre a adequação teórica e metodológica no processo de ensino e aprendizagem. Se aceita que a utilização de dados secundários (revisão da literatura) para o aprofundamento do tema e do problema proposto - com foco nos descritores e categorias chave para a análise -, reveste-se de certa base empírica indireta, por meio dos autores explorados ${ }^{3}$. As tendências indicadas como conclusivas nesse estudo traduzem um compartilhamento de resultados que as vincula ao diálogo atual sobre o ensino-aprendizagem da Sociologia, e nele as possibilidades da forma monitoria.

Assim, o texto se desenvolve com o balastro da leitura não sistemática da literatura sobre o tema do ensino da Sociologia e da monitoria acadêmica. O objetivo não é o de apresentar o estado da arte do tema, mas, discutir a possibilidade de favorecimento à positividade do ensino e da aprendizagem da Sociologia no EM, pelo exercício da monitoria. Para tanto, discute aspectos da relação entre a forma de ensino monitoria e o status (lugar) dessa disciplina nesse grau de ensino (e em menor proporção no Ensino Superior), realçando o processo de "autorregulação". Concebida como um princípio constitutivo da monitoria e de processos de ensino e aprendizagem entre pares, pressupõe-se ser a "autorregulação" favorável àquela positivação.

\footnotetext{
${ }^{1}$ Ver, entre outros, Lins e Gonçalves (2007), "A Sociologia da Saúde na formação dos profissionais de Enfermagem". No EM, por exemplo, Oliveira e Jardim (2008) esclarecem como grande parte da disciplina Sociologia consolida-se com as pressões dos movimentos sociais, liderados principalmente por cientistas sociais ou sociólogos.

${ }^{2}$ Atividades de monitoria realizadas durante ano de 2014 contaram com a participação da discente da Universidade de Pernambuco (UPE - Campus Petrolina) Laila Angélica de Lima, sendo uma parte desenvolvida no grupo tutorial, onde se trabalhou os "Sete passos" do método ABP - Aprendizagem Baseada e Problema - tradução usual brasileira para Problem-Based Learning.

${ }^{3}$ Apesar das vivências, percepções, experiências, registradas na prática da monitoria (vide Rodapé 4) pela autora (Profa. Maria Antonieta A. Souza) durante a orientação da aluna, as informações do estudo têm base secundária.
} 
A MONITORIA | Maria Antoniêta Albuquerque de Souza e Virgínia Pereira da Silva de Ávila

Essa afirmação não causaria estranhamento para nenhum 'teóricos' da educação porque grande parte dos estudos sobre o tema "monitoria" está publicada sob a forma de relato de experiência (MATOSO, 2014; SILVA; LACERDA, 2015) ou de forma mista: relato acompanhado de pesquisa com os sujeitos participantes da vivência relatada (FRISON; MORAES, 2010; CUNHA JÚNIOR, 2009). Além disso, predominam as vivências no meio acadêmico da graduação em detrimento de outros níveis e modalidades de ensino. Matoso (2014), por exemplo, mesmo preocupado em discutir a monitoria enquanto um instrumento de aprendizagem para a formação e o desenvolvimento do acadêmico, não deixa de destacar a importância da função de mediação professor-aluno(s), nas salas de aulas práticas e extraclasse, baseando-se nos estudos de Schneider sobre a monitoria no ensino 4 .

Recentemente, a Resolução de $n^{\circ} 2$, de 30 de janeiro de 2012 define as Diretrizes Curriculares Nacionais para o Ensino Médio (DCN do EM) estabelecendo a organização curricular desse nível de formação em áreas do conhecimento, a saber: linguagens, matemática, ciências da natureza e ciências humanas. Determinados pela legislação nacional orienta-se que os componentes obrigatórios devem ser abordados em uma ou mais dessas áreas na composição do currículo, devendo a Sociologia estar presente em todos os anos do EM. Assim, as escolas passaram e ainda passam por modificações para adequar os conteúdos sociológicos ao currículo (ou o currículo à Sociologia), uma vez que, em consequência, outras matérias tiveram (ou terão) as cargas horárias reduzidas.

No Capítulo II. Art. 14 da citada DCN (BRASIL, 2012a), definem-se as diferentes formas de oferta e de organização do EM, ao qual deve ser assegurada a sua função formativa para todos os estudantes. Pode se organizar o EM em tempos escolares no formato de séries anuais, períodos semestrais, ciclos, módulos, alternância regular de períodos de estudos, grupos não seriados, com base na idade, na competência e em outros critérios, ou por forma diversificada de organização, sempre que o interesse do processo de aprendizagem requerer. Encontra-se, pois, possibilidades para lugares apropriados à monitoria e à formação de grupos tutoriais no EM, como os constituintes da Aprendizagem Baseada em Problemas (ABP).

A tutoria, entendida como responsabilidade do mestre pelo aluno até torná-lo independente e capaz de ensinar outras pessoas, emerge com a universidade e, ao longo dos séculos, tem se valorizado enquanto qualificadora do processo pedagógico. Hoje, entre outras perspectivas, também, se acredita que a tutoria sobrepõe a formação humanística (cuidativa) e a técnico-científica (educativa), numa dimensão hermenêutico-emancipatória, compatível com a Pedagogia do Cuidado (GEIB et al., 2007). O tutor tem por função estimular o processo de aprendizagem dos alunos e auxiliar no desenvolvimento de habilidades e capacitações dos mesmos.

Nesse sentido, e resguardados os limites, parece reduzida, senão inexpressiva, a distância entre os conceitos tutoria e monitoria no processo pedagógico. Considera-se que a prática da monitoria constitui um processo com interfaces das dimensões política, tecnológica e humana, por meio do qual os alunos se auxiliam na situação ensino-aprendizagem. Ademais, o trabalho de monitoria busca contribuir para o desenvolvimento de competências pedagógicas, auxiliando, também, na apreensão e produção de conhecimentos.

No exame de Candau (1986), a monitoria (acadêmica) surge como um procedimento pedagógico que tem se mostrado eficaz e eficiente para responder as questões de ordem política, técnica e humana. Do mesmo modo é que, desenvolvida entre os pares, deve ser entendida como um sistema no qual os parceiros, mutuamente se ensinam e aprendem, em uma proposta de trabalho em que todos participam, discutem e refletem conjuntamente, sob a orientação do professor.

${ }^{4}$ Fundamenta-se nos princípios da perspectiva crítico-progressista da prática pedagógica. 
A MONITORIA | Maria Antoniêta Albuquerque de Souza e Virgínia Pereira da Silva de Ávila

Em quaisquer casos, em um programa de monitoria dois destacados papéis são atribuídos ao aluno-monitor. O primeiro é o de facilitador da aprendizagem, um mediador junto aos seus pares ${ }^{5}$. Não se trata de mera interposição ou intermediação nas relações entre os atores (professor-aluno) na aprendizagem. Contrariamente, a mediação constitui-se em duas faces. A primeira face, na própria relação interativa entre os indivíduos ou grupos participantes de uma ação ou atividade mediados pela linguagem. A segunda face constitui-se na chance de, nessa interação, os atores envolvidos se apropriarem dos instrumentos compartilhados (CUNHA JÚNIOR, 2009). No jogo interativo da vida escolar em uma instituição específica, a tarefa da mediação é facilitada pelo sentimento de pertencimento do monitor à categoria aluno. Essa condição facilita o compartilhamento dos espaços extraclasses comuns, no interior de uma unidade de ensino. A biblioteca, os corredores, os ambientes de lazer, o pátio, a cantina, são os espaços comuns mais disputados.

O segundo papel relevanteatribuídoao monitorcorrespondeàfunçãodeconstanteatualizaçãodos conteúdos ministrados pelo professor da disciplina, pois, no processo de "mediação" professor-monitor-aluno, há pouco lugar para o descrédito, afinal, a repetição de "falhas" é considerada inadmissível. Como efeito, a consciência pessoal desse risco produz no monitor percepções e sensações de incerteza, medo, ansiedade, solidão, incidentes na autoconfiança e no desempenho da monitoria.

A busca de superação da constante ameaça da "falha" suscita que se estabeleçam estratégias para desenvolver ações que facilitem e promovam a tranquilidade e voltem-se à produção de realizações, descobertas, aprendizagens. Explorar estratégias de "autorregulação" concorre para desassombrar esse temor desestabilizador da monitoria, sobretudo quando o ensino da Sociologia se reveste do imaginário da carga teórica, da abstração dos conteúdos e das dificuldades na formação para o magistério. Pressupondo-se que o papel do aluno-monitor (de facilitador da aprendizagem, de mediador junto aos pares) pode favorecer o interesse pelo estudo da Sociologia e a compreensão de sua utilidade para a vida e a preparação profissional, aquela se torna uma questão, também, interessante.

\section{2 | APENAS UMA PALAVRA BASTA PARA UM BOM APRENDIZ}

Com a obrigatoriedade legal (Lei $n^{\circ} 11.684$, de 02 de junho de 2008) da Sociologia no EM, nos cursos técnicos ou não, públicos ou privados, brasileiros, muitas discussões fizeram-se e se fazem ainda urgentes para a sua adequação, o que ocorre em virtude da necessidade de alterações na regência de classe, no programa da disciplina e da redução expressiva na carga-horária de outras disciplinas (MASCARENHAS, 2012, OLIVEIRA; JARDIM, 2008).

Observe-se que, não obstante à criação e a luta das entidades de defesa dos profissionais sociólogos, surgidas em vários pontos do país, foi na década de 1980 (Lei $n^{\circ}$ 6.888/1980; e decreto $\mathrm{n}^{\circ} 89.531 / 1984$ que regulamenta) que se conquistou a obrigatoriedade da disciplina no currículo de todas as escolas brasileiras de EM (OLIVEIRA; JARDIM, 2008). Nesse intermeio destacaram-se dois grupos de profissionais: os "acadêmicos" e os "técnicos"6.

Consequências advieram não somente desse embate profissional e do afastamento (ou as in-

\footnotetext{
${ }^{5} \mathrm{~A}$ mediação orientada na direção processual nunca é puramente instrumental.

${ }^{6}$ Os autores citados anunciam dois grupos: os "sociólogos acadêmicos" defendiam a Sociologia como área de conhecimento científico, em geral localizados nas universidades públicas e nos principais centros de pesquisas; os "técnicos" constituídos pelos formados em Ciências Sociais e que ocupavam espaços tradicionais na administração pública (assessores, administradores, analistas, pesquisadores, entre outras denominações genéricas) e novos espaços no mercado de trabalho (como ONGs e partidos políticos).
} 
A MONITORIA | Maria Antoniêta Albuquerque de Souza e Virgínia Pereira da Silva de Ávila

terrupções) da Sociologia no EM, mas, também, do maior reconhecimento e aproximação da Sociologia com o Ensino Superior. Some-se a isso a repetida reclamação de que na educação brasileira se desenvolve um processo de desvalorização, tanto dos cientistas sociais como, e sobretudo, dos graus anteriores de educação.

Como efeito do exposto, dois aspectos sobressaem ao propósito desse texto. Os prejuízos no desenvolvimento do saber pedagógico e o desconhecimento e a desvalorização da Sociologia na formação do aluno no EM. No momento, tende-se à travessia para a realização de pesquisas que exploram o tema da Sociologia como disciplina nesse grau de ensino. Travessia esta, que segue ao lado de um movimento que discute as questões sobre a necessidade de aproximação da universidade com a formação nessa esfera do sistema de ensino.

Em meio às transformações e as necessidades da sociedade atual, Oliveira e Jardim (2008) indagam pelas condições necessárias ao desenvolvimento do efetivo trabalho do professor de Sociologia do EM e pelas condições em que os mesmos se formam. Apresentam interessantes desafios que não prescindem de mudanças nas práticas docentes, como as mudanças das atividades norteadas pelas políticas de Educação reguladas pelas Diretrizes Curriculares Nacionais e pelos Parâmetros Curriculares Nacionais para o Ensino Médio.

Não será demais lembrar que, após a década de 60, a consolidação das Ciências Sociais no Brasil passa a privilegiar a pesquisa científica e acadêmica, afastando-se do campo escolar. $\mathrm{Em}$ meio às consequências disto, tende-se ao consenso que o sociólogo, mesmo sem possuir os conhecimentos pedagógicos necessários à formação docente, tem condições para "ensinar" Sociologia pelo domínio dos seus conhecimentos específicos. Provavelmente tal crença anuncie a intenção de se evitar uma sobreposição de duas profissões com reduzido valor social: a de cientista social e professor. É que o sentido da expressão "sociólogo/professor" difere de "professor/sociólogo", pela inversão dos termos. A troca de lugar nesse par tende a negativar o lugar do "sociólogo" na hierarquia das profissões e, também, no interior das formações no sistema de ensino. Ou seja, compreende-se que é possível e necessário estabelecer uma equivalência de valores nos significados dos termos dos pares: sociólogo/licenciatura e sociólogo/bacharel (profissão/tipo da graduação; tipo da graduação/profissão). Como consequência da oposição entre os dois termos, o que se vem observando é que a melhor valorização do bacharelado na formação acadêmica do sociólogo ou do cientista social, do ponto de vista da ciência e da profissão, não tem sido suficiente para superar as falhas e os vazios da atuação docente no âmbito do EM (ou mesmo Superior). Nesse aspecto, a formação para docência em Ciências Sociais ou em Sociologia necessita integrar os conhecimentos específicos da área aos conhecimentos da área pedagógica, articulando o ensino, a pesquisa e a extensão. Para tanto, é imperativo uma quebra na cadeia dos sentidos que negativam as ciências sociais e o "professor/sociólogo".

Provavelmente se agregarão ganhos simbólicos à disciplina ante o conjunto curricular do EM, assim como de "professor sociólogo". Por essa razão, a simplificação da linguagem, o esforço para a significação dos conceitos, o engajamento dos alunos e professores de Sociologia ou/e das Ciências Sociais no processo de ensino, a aprendizagem compartilhada, fazem-se importantes na compreensão e definição curricular do EM (e Superior).

Sabe-se que as metas pedagógicas sugeridas na "monitoria entre pares" são mediadas pelo professor e pelo aluno-monitor. Sendo parte do processo de aprendizagem, as metas precisam estimular e desenvolver: a capacidade para o autoconhecimento para se envolver com as aprendizagens agindo sobre elas ("cognição/metacognição"); devem fazer parte das estratégias para a autoconfiança dos sujeitos envolvidos no ensino-aprendizagem; na mesma perspectiva, as metas precisam considerar as "emoções/ motivações" que mobilizam os sujeitos para agirem numa perspectiva relacional, envolvendo o ambiente, a necessidade e o objeto de satisfação; as metas 
A MONITORIA | Maria Antoniêta Albuquerque de Souza e Virgínia Pereira da Silva de Ávila

devem considerar condições contextuais do processo de ensino e aprendizagem e dos sujeitos particulares. As condições que motivam ou não, na proporção em que interagem com algumas características do sujeito, suas metas, seus modos de realizar uma tarefa (FRISON; MORAES, 2010, p. 152). É nesse sentido que se observa um decisivo elemento do princípio educativo "autorregulador"7.

De acordo com as orientações expressas nos $\mathrm{PCNs}^{8}$ para o Ensino Médio, a disciplina de Sociologia deve ser ministrada conjuntamente com a Antropologia e a Ciência Política, para que se desenvolvam competências e habilidades ancoradas em três eixos - Representação e Comunicação, Investigação e Compreensão, Contextualização Sociocultural. Eixos que podem se alinhar às metas pedagógicas de uma monitoria entre pares, inclusive em ambiente de grupo tutorial (ABP), ambas sob a orientação do professor (BRASIL, 2000). Observe-se a compreensão sintética das pertinências atribuídas aos objetivos dos eixos: Representação e Comunicação, Investigação e Compreensão e Contextualização Sociocultural.

O eixo Representação e Comunicação pressupõe identificar, analisar e comparar os diferentes discursos sobre a realidade: as explicações das Ciências Sociais, amparadas nos vários paradigmas teóricos, e as do senso comum, assim como produzir novos discursos sobre as diferentes realidades sociais, a partir das observações e reflexões realizadas.

O eixo Investigação e Compreensão objetiva construir instrumentos para uma melhor compreensão da vida cotidiana, ampliando a "visão de mundo" e o "horizonte de expectativas", nas relações interpessoais com os vários grupos sociais; construir uma visão mais crítica da indústria cultural e dos meios de comunicação de massa, avaliando o papel ideológico do "marketing" enquanto estratégia de persuasão do consumidor e do próprio eleitor; compreender e valorizar as diferentes manifestações culturais de etnias e segmentos sociais, agindo de modo a preservar o direito à diversidade, enquanto princípio estético, político e ético que supera conflitos e tensões do mundo atual.

Os objetivos apresentados no eixo Contextualização Sociocultural são compreender as transformações no mundo do trabalho e o novo perfil de qualificação exigida, gerados por mudanças na ordem econômica e social, bem como construir a identidade social e política, de modo a viabilizar o exercício da cidadania plena, no contexto do Estado de Direito, atuando para que haja, efetivamente, uma reciprocidade de direitos e deveres entre o poder público e o cidadão e também entre os diferentes grupos.

Do ponto de vista metodológico pressupõe-se, na consideração dos temas dos três eixos, que a ciência sociológica é capaz de promover uma reflexão a respeito da adequação de modelo(s) educaciona(is) do EM, que considera $(\mathrm{m})$ a formação da cidadania e a humanização da população jovem. Mascarenhas (2012) avalia, entretanto que, geralmente, surgem das próprias experiências e vivências no ensino de Sociologia argumentos justificadores dos problemas e das dificuldades expressados em jargões como: "brasileiro detesta estudar", (é) "difícil ensinar em um país que não gosta de ler" [...]. Expressões repetidas sem a problematização suscitada pelo entendimento dos

\footnotetext{
${ }^{7}$ O Ensino Médio, portanto, é a etapa final de uma educação de caráter geral, afinada com a contemporaneidade, com a construção de competências básicas, que situem o educando como sujeito produtor de conhecimento e participante do mundo do trabalho, e com o desenvolvimento da pessoa, como "sujeito em situação" - cidadão (BRASIL, 2000). O próximo estágio, não obrigatório, é o Ensino Superior.

${ }^{8}$ Os Parâmetros Curriculares Nacionais (PCNs) orientam para que a disciplina de Sociologia seja ministrada em todos os anos do Ensino Médio. Do ponto de vista operacional, os componentes curriculares obrigatórios que decorrem da LDB e integram as áreas de conhecimento da Sociologia se referem às Ciências Humanas (História, Geografia, Filosofia). Transversal e integradamente, permeando todo o currículo, apresentam-se os temas: saúde nutricional, envelhecimento, educação ambiental. Quanto à atualização pedagógica, também, faz-se necessária a adoção de metodologias de ensino que estimulem a iniciativa do estudante.
} 
A MONITORIA | Maria Antoniêta Albuquerque de Souza e Virgínia Pereira da Silva de Ávila

seus claros propósitos. Pensa Mascarenhas que a exploração desses jargões se ancora na crença da necessidade do conhecimento sociológico para a formação de uma opinião crítica. Que o mesmo ajuda a desenvolver ou a "criar nos jovens um espírito crítico".

Os estudos realizados pelo autor supracitado também apontam para as dificuldades dos professores do EM de Sociologia quanto a o que, como e quando ensinar. Admite a existência de uma desarticulação entre os campos de conhecimentos específicos das Ciências Sociais e da Educação. Como efeito, acredita Mascarenhas que persiste vigorosamente, no currículo do EM, a lógica na associação entre a resistência dos alunos com relação à disciplina Sociologia, uma vez que se observa no domínio dos conhecimentos e práticas

[...] à ausência de referenciais de conteúdos, metodologias de ensino, bibliografia adequada e à desvalorização das licenciaturas que não dão conta de articular os conhecimentos específicos e os pedagógicos necessários para uma eficaz formação docente. (MASCARENHAS, 2012, p. 25).

A questão da formação adequada do professor apresenta-se, para esse autor, crucial à aceitação e à compreensão dos alunos em dois aspectos. Primeiro, nos currículos escolares, onde transparece o dilema da relação de adequação na transmissão da teoria e a sua contextualização. E segundo, para Mascarenhas, nota-se explicitado na aceitação e na compreensão dos alunos sobre a disciplina Sociologia nos currículos escolares. O cabível registro sobre esses aspectos, de um dos sujeitos participantes da pesquisa de Mascarenhas, justifica a demasia da citação.

Sempre tive muito cuidado com a questão de aulas teóricas. A necessidade da contextu-
alização acaba vindo à tona em situações como essa, onde o aluno do Ensino Médio, que
não está lá para se especializar em sociologia, acaba ficando entediado com todo aquele
conjunto de conceitos. Acho a teoria fundamental, mesmo no Ensino Médio. Conceitos
e temáticas que se afirmam tanto nos PCNs como nos programas estaduais são de fun-
damental importância e só ganham sentido dentro de uma contextualização. Por isso é
necessário, principalmente no Ensino Médio, a adoção de práticas que contextualizem os
conceitos, dando alma e sentido a algo que inicialmente, se apresenta apenas como uma
abstração nem sempre tão fácil de se compreender. Não podemos entupir nossos alunos
com teorias e abstrações que em determinados momentos nem nós mesmos compreen-
demos muito bem. Mas também não podemos nos dar ao luxo de deixar de lado as ferra-
mentas teóricas produzidas pela sociologia dando ênfase apenas na leitura e no debate
sem lastro conceitual. Devemos nos lembrar sempre que nosso conteúdo é justamente
esse conjunto de conceitos, essas estruturas intelectuais e que a contextualização é o
mecanismo fundamental para a compreensão de seus mecanismos de funcionamento.
(MASCARENHAS, 2012, p. 5).

Ressaltam-se, dos (des)entendimentos acima, os tons afetivos e relacionais que podem ser benéficos à superação de obstáculos ao ensino e aprendizagem, uma vez que podem contribuir para o equilíbrio da autoconfiança dos alunos e do professor. A segurança nessas posições identitárias pode estimular a motivação para a aprendizagem e acrescer o gosto dos sujeitos da educação (professor, aluno, monitor ou tutor) pela investigação (pesquisa) e estudos. O que favorece os processos de mudanças incidentes na visão e na postura ante o mundo e as demais disciplinas do currículo escolar.

Mesmo assim, não deve ser silenciado o frequente estado de insegurança pessoal em face da assombrada "falha", constitutiva da necessidade da função de constante atualização, pelo monitor, dos conteúdos ministrados pelo professor. De outra forma, para que a monitoria possa se realizar no ensino e na aprendizagem, explorando os principais componentes minimizadores da constante "falta", se requer que as estratégias sejam adotadas e aceitas pelos atores envolvidos diretamente no 
A MONITORIA | Maria Antoniêta Albuquerque de Souza e Virgínia Pereira da Silva de Ávila

processo: o programa de monitoria, o monitor, o professor, o conjunto dos alunos, e mesmo a gestão da escola. Neste movimento, seria o princípio da "autorregulação" elemento favorável à minimização do problema da "falta" que afeta a autoconfiança nessa forma de ensino monitoria?

\section{3 | MONITORIA E A MEDIAÇÃO AUTORREGULADA NA APRENDIZAGEM COMO ESTÍMULO AO ENSINO DE SOCIOLOGIA}

Considerar a prática da monitoria uma estratégia que colabora com a vivência dos processos de autorregulação da aprendizagem discente ${ }^{9}$ (FRISON; MORAES, 2010) convoca duas lembranças associadas a três importantes sujeitos da educação, o professor-aluno-monitor aluno, quais sejam: a lembrança daquela característica constitutiva do status da mediação em monitoria - os momentos de insegurança pessoal do discente, e sobre a opção do professor para trabalhar com essa modalidade de ensino.

Para o professor, essa escolha é idealizada como uma estratégia que possibilita ao aluno vivências pedagógicas e profissionais. Desse modo, precisa liderar a orientação, a mediação e a coordenação do processo de aprendizagem, incorporando a ajuda ao aluno para que assuma tranquilamente as responsabilidades na autoaprendizagem. Isso significa que a perspectiva do papel do professor sugere a presença e a constante ação de formação e avaliação do(a) monitor(ia), em direção a processos autorreguladores das aprendizagens, inclusive, atentos à negatividade de possíveis incidências práticas do "erro". Na maioria das vezes, como observa Freire e Faundez (1985), o erro só aparece associado a um tipo de avaliação em que o professor analisa os trabalhos dos alunos em termos de certo/errado. Para ele, é necessário um ensino que estimule a pergunta, que desenvolva a curiosidade de aprender.

No ensino entre pares, a troca entre os "desigualmente iguais" chama ao "desafio de aprender a aprender, para o risco de assumir a própria autoria" (FRISON; MORAES, 2010, p. 148). Aprender a aprender implica em tomar para si mesmo os motivos e os meios que conduzem ao aprender. Assim, argumentam as autoras, que a monitoria apresenta em seu cerne um princípio regulatório. Tal princípio resulta da interação das variáveis pessoais na forma de aprendizagem regulada pelo próprio aluno, com conhecimento, competência, motivação ${ }^{10}$.

Os processos podem ser incentivados em três vetores convergentes: a experiência; o ensino (envolvendo a mediação, a conversa, a orientação); as práticas educativas que intencionalmente (ou não) provoquem esses mecanismos. No caso, não somente o aluno precisa querer aprender. O professor necessita da disposição para assumir a responsabilidade da proposta, e assim reduzir os efeitos dos problemas e questões pertinentes à disciplina de Sociologia no Ensino Médio e Superior. Não obstante, trata-se da valorização da monitoria como uma estratégia para a autorregulação de práticas autorrefletidas no ensino-aprendizagem, onde o estímulo para a reflexão (revelação) insurge nas situações concretas da experiência cotidiana escolar ou na academia.

\footnotetext{
${ }^{9} \mathrm{Em}$ Aprendizagem autorregulada: diferentes leituras teóricas, Couceiro Figueira (1997, p. 47-77) entende a forma de aprendizagem autorreguladora como "[...] à possibilidade de os alunos serem metacognitiva, motivacional e comportamentalmente proativos, reguladores de seus processos de aprendizagem, participarem ativamente desse processo e se tornarem promotores do próprio desempenho".

${ }^{10} \mathrm{Na}$ prática da monitoria estas variáveis possibilitam o planejamento, a organização e o controle e a avaliação dos processos utilizados na aprendizagem, dos resultados conseguidos e das variáveis contextuais. A consideração do princípio regulatório "estimula e cria as condições para formas estratégicas e intencionais da ação". Para desenvolver esse argumento as autoras baseiam-se no trabalho realizado por Silva, Simão e Sá (2004) intitulado "A auto-regulação da aprendizagem: estudos teóricos e empíricos".
} 
A MONITORIA | Maria Antoniêta Albuquerque de Souza e Virgínia Pereira da Silva de Ávila

Nessa perspectiva, Frison e Moraes (2010) chamam a atenção para três aspectos importantes da monitoria acadêmica, que se podem considerar possibilidades a serem exploradas no ensino de Sociologia no Ensino Médio, sob a orientação do professor. Consideram que: a mediação realizada por monitores pode oferecer aos alunos a possibilidade de autorregular suas aprendizagens; os monitores e seus pares conseguem se relacionar mais rapidamente, abstrair com maior clareza e entender as questões que são colocadas no cotidiano escolar, sendo a interação e a cooperação estratégias que mobilizam o ensino-aprendizagem e que o valor formativo da autorregulação da aprendizagem e o aumento do interesse para aprender, podem ser apreendidos no trabalho realizado pelo aluno no processo de formação do autoconceito e da autoformação, possibilitadas pela aprendizagem compartilhada. Esse processo autorregulador na educação "[...] envolve autonomia, iniciativa, planejamento, organização" (FRISON; MORAES, 2010, p. 147), e certa responsabilidade do sujeito da ação pela sua aprendizagem, característicos da monitoria.

Por seu turno, a princípio os programas de monitoria se guiam por critérios julgados estimulantes à autonomia na preparação para a profissão. Pode-se considerá-la uma espécie de dispositivo para o exercício da responsabilidade e do compromisso com a própria formação e a formação do outro. Assim, no esforço regulatório institucional tende-se a requerer e controlar atributos de esforços pessoais - a competência, a dedicação, o interesse e a disponibilidade, constitutivos da necessidade da busca constante de construção de conhecimentos e de desenvolvimento de competências. Características identitárias essas não menos exigidas do monitorando pelos alunos.

Aavaliação realizada notrabalho de Frison eMoraes(2010)exemplificaalgum efeito das exigências acima descritas. Acentua que o aluno (graduando) tende a achar significativa a forma de aprendizagem monitoria porque nela a comunicação é facilitada. Ou seja, a linguagem utilizada é mais clara do que a dos professores e as relações estabelecidas entre os conteúdos e o cotidiano, possibilitando no aluno a percepção de que as suas dificuldades são próprias do processo de aprendizagem.

Desse modo, a perspectiva da aprendizagem partilhada contribui para que o aluno compreenda a posição do seu lugar no processo de ensino e aprendizagem. No viés interativo da aprendizagem esse ator melhor se situa como o sujeito que age (não o objeto), em constante busca de aperfeiçoamento.

Nesse ambiente de construção da aprendizagem, a forma de ensino monitoria entre pares favorece a sensação, consciente e não, de segurança e colaboração. Uma vez que o aluno monitorando, ou não, pode perceber-se em situação colaborativa (de ajuda, orientação) na direção das intenções educativas eleitas. Intenções que podem vir a se concretizar no planejamento, na sistematização, na realização coletiva de atividades variadas como: jogos, exercícios, solução de problemas. Porém, essas não prescindem das operações (mentais) que envolvem as características identitárias da monitoria: a competência, a capacidade de utilização de habilidades e o emprego de atitudes ${ }^{11}$ adequadas às tarefas (o interesse, a disponibilidade) e o conhecimento, para aprender e seguir aprendendo ativa, colaborativa e interativamente.

Orientada e compartilhada com responsabilidade, também com o professor, aceitam-se que as práticas de monitoria no ensino e na aprendizagem da Sociologia podem propiciar nos alunos a capacidade para estabelecer metas, desenvolver estratégias e criar alguma condição para que o processo de aprendizagem se efetive. Em constante atualização, de forma proveitosa e reflexiva, mais solidário e menos dificultoso para os sujeitos envolvidos.

\footnotetext{
${ }^{11}$ Utiliza-se neste lugar do texto a compreensão que são "atitudes de valores" relativas às: "[...] boas relações interpessoais, a autoestima, o respeito aos outros, o cumprimento das normas de convivência, a autonomia, o saber comportar-se, a solidariedade e a tolerância". (ESCOLA CRESCIMENTO, 2015).
} 
A MONITORIA | Maria Antoniêta Albuquerque de Souza e Virgínia Pereira da Silva de Ávila

\section{4 | CONSIDERAÇÕES FINAIS}

A monitoria em Sociologia requer a articulação de três fatores, quais sejam o constante acompanhamento do monitor pelo professor, o cuidado na formação do aluno-monitor e a vontade institucional. Na produção das práticas e experiências da monitoria (e nas suas publicações) é importante perscrutar os elementos favoráveis à reflexão como: as teorias a elas subjacentes e/ou explicitadas, os sentidos de suas funções, a importância atribuída ou relegada à pesquisa e extensão (especialmente a monitoria acadêmica) e as suas significações para os principais sujeitos envolvidos no campo da educação. A adoção de atitudes dessa natureza fortalece as chances para que as quatro áreas de conhecimento que orientam a organização curricular no EM sejam mais claramente observadas, e os conteúdos da disciplina Sociologia sejam aprendidos em linguagem menos abstrata e mais interativa.

Os PCNs que orientam o ensino de Sociologia reforçam temas transversais importantes para a vida e que são assim muito enriquecidos. A mesma lógica de organização curricular integrativa deve acompanhar o projeto pedagógico de cursos de graduação em Sociologia, conforme recomendados pelas respectivas DCNs. Sendo assim, um programa de monitoria deve ter por objetivo institucional despertar o aluno para o exercício da docência, conduzindo-o por processos cujos caminhos são desenhados por sua participação ativa. Espera-se que as atividades práticas associem o aluno ao ensino de modo a apropriar-se de habilidades e competências necessárias ao exercício futuro da docência.

No exercício de um programa de monitoria é importante guardar a perspectiva da constante reflexão e avaliação das práticas regidas pelo princípio da autorregulação, possibilitada por essa modalidade, como estratégia para o ensino de Sociologia no grau Médio ou Superior, o que se torna substancial para que se estabeleçam os vínculos entre a aprendizagem compartilhada (monitoria) entre pares e a autorregulação da aprendizagem, contextualizados no campo disciplinar da Sociologia.

A relação que tende a ajustar medidas interativas na comunicação entre alunos e professores, assim como na organização de conteúdos curriculares é fundamentalmente importante para a produção de significados geradores de interesses e/ou de necessidades de aprendizagem, em ambiente prazeroso para o ensino-aprendizagem. 
A MONITORIA | Maria Antoniêta Albuquerque de Souza e Virgínia Pereira da Silva de Ávila

\section{Referências}

CANDAU, V. M. F. A didática e a formação de educadores: da exaltação à negação: a busca da relevância. In: CANDAU, V. M. F. (Org.). A didática em questão. Petrópolis: Vozes, 1986. p. 12-22.

CUNHA JÚNIOR, F. R. da. Monitoria: uma possibilidade de transformação no ensino-aprendizagem no ensino médio. 2009. 133 f. Dissertação (Mestrado em Linguística Aplicada e Estudos da Linguagem) - Pontifícia Universidade Católica de São Paulo, São Paulo, 2009.

BRASIL. Decreto $n^{\circ} 89.531$, de 5 de abril de 1984. Regulamenta a Lei $n^{\circ} 6.888$, de 10 de dezembro de 1980, que dispõe sobre o exercício da profissão de sociólogo e dá outras providências. Diário Oficial da União. Brasília, DF, 9 abr. 1984.

Lei $n^{\circ} 6.888$, de 10 de dezembro de 1980. Dispõe sobre o exercício da profissão de Sociólogo e dá outras providências. Diário Oficial da União. Brasília, DF, 11 dez. 1980.

. Lei n ${ }^{\circ} 9.394$, de 20 de dezembro de 1996. Estabelece as diretrizes e bases da educação nacional. Diário Oficial da União. Brasília, DF, 23 dez. 1996. Disponível em: <http://www.jusbrasil.com.br/diarios/1541961/pg-1secao-1-diario-oficial-da-uniao-dou-de-23-12-1996>. Acesso em: 2 maio 2015.

Lei $n^{\circ} 11.684$, de 02 de junho de 2008. Altera o art. 36 da Lei no 9.394, de 20 de dezembro de 1996, que estabelece as diretrizes e bases da educação nacional, para incluir a Filosofia e a Sociologia como disciplinas obrigatórias nos currículos do ensino médio. Diário Oficial da União. Brasília, DF, 3 jun. 2008. Disponível em: <http://www.planalto.gov.br/ccivil_03/_Ato20072010/2008/Lei/L11684.htm>. Acesso em: 2 maio 2015.

Ministério da Educação. Parâmetros curriculares nacionais - ensino médio. Brasília, DF: MEC, 2000. Disponível em: <http://portal.mec.gov.br/seb/arquivos/ pdf/blegais.pdf>. Acesso em: 2 set. 2015.

. Parecer CNE/CEB $n^{\circ} 7$, aprovado em 7 de abril de 2010. Diretrizes curriculares nacionais gerais para a educação básica. Diário Oficial da União, Brasília, DF, 9 jul. 2010. Seção 1, Pág.10.

. Parecer CNE/CP no 8, aprovado em 6 de março de 2012. Diretrizes nacionais para a educação em direitos humanos. Diário Oficial da União, Brasília, DF, 30 maio 2012b. Seção 1, Pág. 33.

Resolução CNE/CEB $n^{\circ} 2$, de 30 de janeiro 2012. Define diretrizes curriculares nacionais para $\mathrm{O}$ ensino médio. Diário Oficial da União, Brasília, DF, 31 jan. 2012a. Seção 1, p. 20. Disponível em: <http://www. jusbrasil.com.br/diarios/33989713/dou-secao-1-31-012012-pg-20>. Acesso em: 1 set. 2015.
ESCOLA CRESCIMENTO. Programa de convivência e solidariedade: tutoria. São Luís, 2015. Disponível em: $<$ http:// www.crescimento.com.br/ensino-fundamental-ii/ tutoria/>. Acesso em: 22 out. 2015.

FREIRE, P.; FAUNDEZ, A. Por uma pedagogia da pergunta. Rio de Janeiro: Paz e Terra, 1985. (Coleção Educação e Comunicação: v. 15)

FRISON, L. M. B.; MORAES, M. A. C. de. As práticas de monitoria como possibilitadoras dos processos de autorregulação das aprendizagens discentes. Poíesis Pedagógica, v. 8, n. 2, p. 144-158, ago./dez. 2010. Disponível em: <https://www.revistas.ufg.br/index.php?journal=poiesis $>$. Acesso em: 22 out. 2015.

GEIB, L. T. C. et al. A tutoria acadêmica no contexto histórico da Educação. Revista Brasileira de Enfermagem, Brasília, v. 60, n. 2, p. 217-220, mar./abr. 2007. Disponível em: <http://www.scielo.br/scielo.php?script=sci_arttext\&pid=S0034-71672007000200017\&lng=en\&nrm=iso > . Acesso em: 15 set. 2015.

LINS, H. de A.; GONÇALVES, A. G. B. A sociologia (da saúde) na formação de profissionais de enfermagem. In: ENCONTRO DE EXTENSÃO, 9.; ENCONTRO DE INICIAÇÃO À DOCÊNCIA, 10., 2007, João Pessoa. Anais... João Pessoa: UFPB, 2007. Disponível em: <http://www. prac.ufpb.br/anais/IXEnex/iniciacao/documentos/anais/ 6.SAUDE/ 6CCHLADCSMT01.pdf>. Acesso em: 21 out. 2015.

MATOSO, L. M. L. A importância da monitoria na formação acadêmica do monitor: um relato de experiência. Catussaba, ano 3, v. 3, n. 2, p. 77-83, 2014. Disponível em: <https://repositorio.unp.br/index.php/catussaba/article/view/567/461>. Acesso em: 21 out. de 2015.

OLIVEIRA, O. F. de; JARDIM, A. de P. O retorno da sociologia no ensino médio no Rio de Janeiro: uma luta que merece ser pautada! Perspectiva Sociológica, ano 1, n. 2, p. 1-15, 2008. Disponível em: <http://www.cp2.g12.br/ UAs/se/departamentos/sociologia/pespectiva_sociologica/Numero2/Artigos/Retorno\%20da\%20Sociologia\%20 $\% 20-\% 200$ tair\%20e\%20Jardim.pdf >. Acesso em: 25 ago. 2015.

SILVA, A. L. da; SIMÃO, A. M. V.; SÁ, I. A auto-regulação da aprendizagem: estudos teóricos e empíricos. Intermeio: Revista do Mestrado em Educação, Campo Grande, MS, v. 10, n. 19, p. 58-74, 2004.

SILVA, C. B. da; LACERDA, A. M. Monitoria na disciplina investigação em psicologia I: um relato de experiência. HumanÆE: Questões controversas do mundo contemporâneo, v. 9, n. 1, p. 1-9, 2015. Disponível em: $<$ http://humanae.esuda.com.br/index.php/humanae/article/view/89/90.\%20Acesso $\% 20 \mathrm{em} \% 2021 \% 20$ de $\% 20$ outubro\%20de\%202015>. Acesso em: 21 out. 2015. 